\title{
Micro organisms living in zinc contaminated soil - a review
}

\author{
Akhilesh Joshi ${ }^{1}$, Priyanka Jaiswal ${ }^{2}$ \\ (Department of Botany, University of Rajasthan, India).
}

\begin{abstract}
Zinc (Zn) has important effect on soil microbes; resultant of its ability to enhance as well as reduce activity depends on its concentration. Heavy metal contamination in soil is affecting animals, human and crop as well. As a result of industrialization for example smelting of metals, mining, electroplating, energy and fuel production, fertilizer, gas exhaust, municipal waste generation sewage and pesticide application, municipal waste generation, etc. Metal pollution is among one of the drastic ecological threats today. In several researches the effects of various solution of Zn on soil microbial communities and activities were analyzed by different concentration of Zn into a surface soil. Research lead to finding that, soil microorganisms is highly sensitive to metal concentration. Metal exerted poisoning impact after high amount was added. Higher concentration resulted slower growth of microbes. Levels of zinc in excess of 500 ppm in soil compete with other essential metals, such as iron and manganese for plant uptake. We can conclude that soil microbial communities and activities can adapt to Zn pollution to a certain extent. The micro organisms can play a substantial job in the remediation of heavy metals and other pollutants.
\end{abstract}

Keywords: Smelting, metal pollution, soil microorganism, heavy metal, remediation, Zinc.

\section{Introduction}

Zinc is a natural component of the earth's crust and an inherent part of our environment. Zinc is present not only in rock and soil, but also in air, water and the biosphere. Plants, animals and humans contain zinc. Minerals and metals are mostly obtained from the earth's crust. The average natural level of zinc in the earth's crust is $70 \mathrm{mg} / \mathrm{kg}$ (dry weight), ranging between 10 and $300 \mathrm{mg} / \mathrm{kg}$. In some areas, zinc has been concentrated to much higher levels by natural geological and geochemical processes $(5-15 \%$ or $50,000-150,000 \mathrm{mg} / \mathrm{kg})$.Such concentrations found at the earth's surface and underground, are being exploited as ore bodies [1]. Over 11 million tons of zinc is produced annually worldwide. Fifty five percent of this amount is used for galvanizing to protect steel from corrosion. Approximately $17 \%$ goes into the production of zinc base alloys, mainly to supply the die casting industry and $12 \%$ to produce brass and bronze. Significant amounts are also utilized in rolled zinc applications including roofing, gutters and down-pipes. The remainder is consumed in compounds such as zinc oxide and zinc sulfate [2]. Economic and Infrastructural development are symbol of progress of the country. As we know industrial products are essential component of the GDP (gross domestic product) of country. Industrial discharge contains various contaminants, which contaminate the surface water, ground water and soil, which lead to meager situation. Levels of the metals in soils around the industrial area were found to be substantially higher than their normal distribution in soil such as $\mathrm{Pb}-293 \mathrm{mg} / \mathrm{kg}, \mathrm{Cr}-240 \mathrm{mg} / \mathrm{kg}, \mathrm{Cu}-298$ $\mathrm{mg} / \mathrm{kg}, \mathrm{Zn}-1,364 \mathrm{mg} / \mathrm{kg}, \mathrm{Sr}-2,694 \mathrm{mg} / \mathrm{kg}$ and $\mathrm{V}-377 \mathrm{mg} / \mathrm{kg}$. Conspicuous concentration of these toxic elements in soil is responsible for the development of toxicity in agriculture products by various ways, which affect back to human life [3]. There are a number of reasons like, the waste are not safely treated is one of the reasons, which is mainly caused by the unavailability of highly efficient and economic waste treatment technology. Among the most industrial equipments the Textile and leather, Fertilizers, Pesticides, insecticides Plastic-based production are major emitters of Zinc contamination.

Microorganisms are prerequisite for the functioning of any ecosystem; hence factors that exert affects on their diversity and gene expression are of main focus. Study of microbial responses has been mostly recommended as an indicator of ecosystem disturbance as microbes respond instantly to environmental disturbance. Enzyme assay is used in the assessment of ecotoxicological impacts of environmental consequences [4].

In the initial manner, research demonstrates that both low (1 ppm) and high (500-2000 ppm) levels of heavy metals in soil could shift a lot the makeup of a microbial community, instantly soil diversity. Several classes of microbes (such as denitrification-capable bacteria) appear to be affected their biogeochemical cycle to a greater extent than generalized microbial community. It also appears that the heavy metals affect microbial communities in a threshold like manner, suggesting the presence of sub-communities with different levels of metal tolerance [5].

Micro organisms can sense variety of chemical signals in there surrounding. Depending on kind of signal is there, they shows a different action for example can move toward higher concentration of chemical as well as could repel itself in anti direction of toxic chemical. Many of these classes of chemicals play key signals 
as plant-synthesized signals that initiate association between organism and plant including tumor formation by Agrobacterium tumefaciens and nodulation by Rhizobium. Soil bacteria are also attracted to various aromatic pollutants, such as benzene, naphthalene and chlorinated herbicides, leads to degradation of these compounds [6].

\section{Microbial diversity on Zinc contaminated soil and its impact}

As a main Biosphere component Zinc (Zn) plays a special role in soil ecology and fertility because it can support the growth of soil organisms or inhibit their growth depending on its concentrations. In recent studies, the effects of different concentrations of $\mathrm{Zn}$ on soil microbial communities and activities were analyzed by loading different doses of $\mathrm{Zn}(160-6000 \mathrm{microg} / \mathrm{g})$ into a wheat surface soil. The microbial metabolic process revealed a significant bimodal pattern at high concentrations of $\mathrm{Zn}(>1920 \mathrm{microg} / \mathrm{g})$. This phenomenon suggested that soil microorganisms are very sensitive to zincous poisoning. After a variety of soil sample were tested and assessed, the results showed slower bacterial growth in soil cultures polluted with high levels of $\mathrm{Zn}$. In addition, two kinds of fungi were identified by morphology and glomalin-related soil protein content in the $\mathrm{Zn}$-contaminated soil. The growth of first one was inhibited with increase in Zn concentration. By contrast, the second kind could survive and continue to grow with increasing doses of $\mathrm{Zn}$ at $160-1920 \mathrm{microg} / \mathrm{g}$ and its growth began to decline with further increase in $\mathrm{Zn}$ concentration [7].

Micro organisms are present all over and in every erratic condition exist on earth either it could be depth of ocean or mountain height they have ability to survive everywhere. Examination of soil cores that have the history of contamination with heavy metals which were mixed in soil from an explosives factory, many isolates $(n=501)$ from the five soil samples survived sub culturing and were identified by Fatty Acid Methyl Esterase (FAME) analysis. After fatty acid profiling, these data were used to divide the isolates into broad taxonomic groupings. A total of 20 genera were identified from the five samples and used to assign each of the isolates to broad taxonomic groups: these were Arthrobacter, Bacillus, Brevibacterium, Brochothrix, Comamonas, Cytophaga, Deinococcus, Enterobacter, Hafnia, Micrococcus, Mycobacterium, Nocardia, Pseudomonas, Rathayibacter, Rhodococcus, Salmonella, Serratia, Staphylococcus, Variovorax, and Xanthomonas. In particular, Firmicutes (mainly Bacillus spp.) had a higher relative abundance in the most contaminated samples, whereas the Gamma proteobacteria (mainly Pseudomonas spp. and a Xanthomonas sp.) increased in relative abundance in the least-contaminated samples [8].

As, it is well understood that, metal ions have immense significance in metabolism as they act as cofactors of several enzymes involved in catalysis of life driving cascades of life. Heavy metals have tendency to attach with -SH group, once reaching the cytoplasm, attaining there minimal inhibiting concentration (MIC) they bound with the -SH group, the metals may inhibit the activity of enzyme [9]. Studies suggest that high Zn concentration has put an effect on the enzyme level. Taking an example of catalytic efficiency of aminopeptidase, toxic effect of $\mathrm{Zn}$ at high concentration that could involve masking of active parts the enzyme or substrate proteins, changing the conformation of the enzyme structure and competing with cation activators connected with the formation of a substrate enzyme complex. Some aminopeptidases are known to be metallozymes that cleave $\mathrm{NH}_{2}$-terminal basic residues from proteins and oligopeptidase substrates. Bacteria in seawater having Aminopeptidase have $\mathrm{Zn}$ as cofactor and thus it is suggest that, it is regulated by $\mathrm{Zn}$ have an adaptation of bacteria to heavy metal occurs in the marine environment. Therefore $\mathrm{Zn}$ contamination inhibit the proteolytic enzyme observed would have affect the biogeochemical cycle [10]. In a similar study, the rate of dehydrogenase activity varied among the bacterial strains. The Gram positive Bacillus had higher rates of dehydrogenase activity than the Gram negative Salmonella and Gram positive Arthrobacter [11].

Environmental change and evolution are two simultaneous processes. Several genomic and sequentially biochemical changes occurs in the small cells. In an another recent genomic sequencing study in response of heavy metal are also carried out and including bacterial as well as fungal strains, allows in searches for genes encoding metal-responsive proteins which lead us to the promoters of genes involved in metal response elements, which would be interesting targets for reporter gene fusions in biomarker establishing. The proteins encoded could be either involved in metal homeostasis and thus being of interest for improving metal resistance of strains for bioremediation or the enzymatic activity of the proteins might lead to new metabolites involved in metal binding, either as chelators or siderophores or as specific detoxification products. Many promoters essential for the induction of several metal resistance determinants are well known now. The strong and tightly controlled mer promoter operates in bacterial mercury resistance [12]; from copper resistant strains of Pseudomonas syringae, the promoter (pcopA) was found [13]. One example for the application of knowledge on metal resistance regulation is a reporter system developed for arsenic detection in environmental samples. This reporter system makes use of the sensory protein ArsR. In Escherichia coli as molecular marker, the luciferinluciferase-based luminescence bioassay could be deployed in natural waters containing arsenic to serve as an indicator for arsenic bioaccumulation [14]. Also, in silico search of metal binding proteins has been performed, using actinobacteria as subjects for a proof of principle. The proteins of 73 different actinobacteria were 
screened for potential metallothioneins or metallohistins, small proteins of less than 100 amino acids containing a high proportion of cysteine and/or histidine residues. In 49 genomes, altogether 99 putative metal sequestrating metallothioneins/metallohistins were identified. Thus, $0.1 \%$ of all proteins occurred in about two thirds of the strains investigated, which can be seen as clear indication that, first, metallothioneins in bacteria are more widely distributed than previously assumed [15] and, second, metallothioneins are not part of the general genomic setup of bacteria but rather have been developed as a result of adaptation toward high metal loads in the environment. Phytochelatins have been identified first in Schizosaccharomyces pombe but were named after their isolation from plants [16].

By keeping in consideration that zinc have certain essential metabolic roles like in micro organism of terrestrial as well as marine, zinc concentration must be remain at a desired level only beyond that it exerts harshening effect by reducing enzyme activity. As we know the substantial effect of zinc concentration the increasing soil concentration due to various mining and industrial effluent must be removed by pre treating effluent to conserve the soil ecology.

\section{Micro organism for removing heavy metals from soil.}

The speedy development and increasing sophistication of various industries in the past century has remarkably increased the amount and complexity of toxic waste effluents, which may be bioremediated by appropriate plants and microbes, either natural occurring or tailor-made for the specific purpose this technology is termed as bioremediation or bioremediation could be explained as any process that uses microorganisms or their enzymes to return the environment altered by contaminants to its original condition. The bioremediation and natural attenuation area has both basic research and field application foci for the environmental biotechnology. The basic research foci are cometabolism, bio-treatability, biotransformation kinetics, and modeling of biogeochemical processes [17].

Heavy metals are toxic and can be harmful for organisms. For this reason, a number of organisms including bacteria develop processes which are able to withstand the effects of these pollutants. An accumulation of heavy metals in different bacterial strains in soil has been observed and could be used in the process of remediation of soils contaminated by heavy-metal-pollutants. Conventional methods for the removal of the heavy metals ions from environment include mainly soil excavation and disposal to landfill, chemical precipitation, electro flotation, ion exchange and reverse osmosis, adsorption onto activated carbon. However, there have been suggesting and testing new methods for remediation of polluted environment based on the organisms, which include bioremediation and phytoremediation. Bioremediation is the use of microorganisms for removing pollutants. Technologies can be generally classified as in situ or ex situ. In situ bioremediation involves treating the contaminated material at the site, while ex situ involves the removal of the contaminated material to be treated elsewhere. Some examples of bioremediation technologies are bioventing, landfarming, bioreactor, composting, bioaugmentation, rhizofiltration and biostimulation [18].

After studies of various types of soil samples various species found to be use full to remove these contamination from soil by biosorption of metals. Biosorption can be defined as the selective sequestering of metal soluble species that result in the immobilization of the metals by microbial cells. Metal sequestering by different parts of the cell can occur via various processes: complexation, chelation, coordination, on exchange, precipitation, reduction. Biosorption is a process with some unique characteristics. It can effectively sequester dissolved metals from very dilute complex solutions with high efficiency. The microbes play a vital role in the remediation of heavy metals and other pollutants. Many microbial strains Pseudomonas species, Staphylococcus species, Bacillus species and Aspergillus niger. After treatment, Pseudomonas sp. and Bacillus species reduced $\mathrm{Cu} 4.165 \mathrm{mg} / \mathrm{l}$ and $3.332 \mathrm{mg} / 1(68 \%$ and $56 \%)$ and $\mathrm{Ni} 5.015 \mathrm{mg} / 1$ and $3.8 \mathrm{mg} / 1(65 \%$ and $48 \%)$ respectively. Aspergillus niger reduced Cd $0.267 \mathrm{mg} / 1(50 \%)$ and Zn $5.988 \mathrm{mg} / 1$ (58\%) whereas Staphylococcus species reduced Cr $4.108 \mathrm{mg} / 1$ (45\%), Cu $2.615 \mathrm{mg} / 1$ (42\%) and $\mathrm{Pb} 0.813 \mathrm{mg} / 1$ (93\%) [19].

The genus Acidocella consists of two species [20], in their study one strain from each of these species and an unclassified strain [21] were used. These strains showed variable degrees of resistance to one or more of four metals: cadmium, copper, nickel, and zinc. Strain GS19h exhibited extreme resistance to both $\mathrm{Cd}$ and $\mathrm{Zn}$ and very high resistance to Ni. Acidocella aminolytica also showed high resistance to these metals. Higher resistance to $\mathrm{Cu}$ was observed in this strain than in other acidophilic hetero trophs [22]. Acidocella facilis showed some resistance only to $\mathrm{Zn}$ and was unable to grow in the presence of other metals at low concentrations. Thus, the Acidocella strains, in general, possess some tolerance to $\mathrm{Zn}$ in comparison with other metal ions. Moreover, among the prokaryotes, Acidocella species strain GS19h exhibited the highest resistance reported thus far to both $\mathrm{Cd}$ and $\mathrm{Zn}$. Some growth parameters of these strains, at a subinhibitory concentration of resistant metals.

A study carried out in which the samples were brought out and MIC was identified different sites of Asia continent. Among the isolates Pseudomonas species were resistance to cadmium $7 \mathrm{mM}$ in TY agar plates. In contrast, only $2 \mathrm{mM} \mathrm{Cd}$ resistance was observed from sewage of Morocco. The present results showed 
Proteus and Acinetobacter species were highly resistant to As $(16,13 \mathrm{mM})$ and Ni $(8 \mathrm{mM})$. But Nickel resistant isolates tolerating were screened from West Bengal, India from serpentine outcrops of central Italy. In this study sewage bacteria were resistant to $\mathrm{Pb}$ at the concentration of $6 \mathrm{mM}$ in TY medium. In contrast, lead resistant isolates were resistant to $0.6 \mathrm{mM}$ and $2.5 \mathrm{mM}$ in minimal medium. Bacteria exposed to high levels of heavy metals in their environment have adapted to this stress by developing various resistance mechanism [23].

The genus Streptomyces is known to be the largest antibiotic-producing group and is still of central importance in the identification of medically relevant natural compounds. With the discovery of streptothricin and streptomycin in the forties of the last century, a systematic screening of antibiotics on isolates of this genus and related taxa was initiated. Interestingly, it was calculated that only a tiny fraction of the antimicrobial compounds the genus is capable to produce has been discovered so far. A total number in the order of 100,000 antibiotics was calculated using a conservative estimate. Metals facilitate secondary metabolism not only in actinobacteria, but in some other prokaryotic taxa and fungal groups as well. The complex effect of metals on secondary metabolism can be seen best with results of product research. A Streptomyces galbus strain producing an antifungal antibiotic is enhanced in production if the fermentation medium is supplemented with copper, zinc or iron, whereas nickel and cadmium addition lead to a reduction of antibiotic concentration in the same strain. Some other experimental Streptomyces strains showed the considerable activity to bio accumulate zinc, Copper and Cadmium, Chromium, Nickel, Strontium and Uranium. To consider whether the microbial species is able to or is not able to remediate the polluted environment, level of metals in bacteria belongs to the one of the main criterion. Trend of analytical techniques is to miniaturize the whole instrument due to the many advantages of small devices including portability, low costs and less demand on service and operations, sufficient sensitivity and selectivity. As the working electrode a hanging mercury drop electrode (HMDE) is commonly used .The HMDE can be also modified with biologically active substances to improve the sensitivity or selectivity of heavy metal ion detection [24].

After a long journey of analysis and identification, microbes that belong to various genera and genus have been recorded for removal of the high contamination of zinc from soil these microbes are Streptomyces, Staphylococcus, Pseudomonas, Bacillus and Aspergillus species.

\section{Metal Resistance Mechanisms}

After more than a decade of studies and research of microbial resistance against heavy metals have, contrasted about methodology for survival in toxic concentration of heavy metal. There were ABC transporter proteins and some microbes harbouring plasmids pertaining resistance specific genes.

The mechanism which is found in Cupriavidus metallidurans $\mathrm{CH} 34$ has given it a advantage for survival under drastic environment and chance of being a model organism. There are several transmembrane protein have reported but here for our concern of work we are mentioning only about P-type ATPases (Hydrolyse ATP) ATP-binding cassette (ABC) transporters for Zn. These proteins are involved in attribute of detoxification [25].

Adaptation of bacteria to heavy metals is attributed to a variety of chromosomal, transposon, and plasmid mediated resistance systems [26]. The incidence of plasmid-bearing strains is more in polluted places than in the unpolluted area [27]. Resistance capability of Pseudomonas aeruginosa RA65 to heavy metals is a result of a genetic factor study of genome and extra chromosomal genetic material revealed that heavy metal resistance of Pseudomonas aeruginosa RM65 is mediated by $9.5 \mathrm{~kb}$ plasmid [28].

Transformation by plasmid obtained from strain GS19h, into Acidiphilium multivorum strain, which resulted in increased resistance as compared to original strain is clear example for involvement of plasmid in resistance to high Zinc concentration 1996 [29].

Ecological changes which are brought down by various human activity which are already mentioned above have resulted in evolution in microbial diversity of that land, the $\mathrm{ABC}$ transporter are common among all organism for different purpose and the plasmid in cells for these remediating process could be considered as drug to cure the diseases of contaminated soil.

\section{Rhizospeares for heavy metal removal}

The rhizosphere is a site, where plant and associated microbe remain associated for need of each other, here enhanced microbial activity that enhances accumulation, transformation, degradation, and biomethylation of metals and other trace elements. Associated organisms in the rhizospheres are known for removal of toxic heavy metals originated from wastewaters through biosorption, sulfide-precipitation and biotransformation (reduction, volatilization). Plants provide a suitable environment, fixed $\mathrm{C}$ in form sugar and other nutrients to the microbes in the rhizosphere. This occurs through root exudation and plant decomposition [30]. Microbial populations are known to affect heavy metals mobility and availability to the plant through release of chelating agents, acidification, phosphate solubilization, and redox changes [31]. Siderophores are metabolic products that 
chelate metal produced by Rhizobacteria, which have significant role in the removing of several heavy metals [32].

\section{Transformation Of Toxic Heavy Metals}

Bacteria have certain abilities to change toxic heavy metals into forms that are more readily taken up into roots. For example, bacteria could enhance Se accumulation in plants by reducing selenate to organic Se, and organoselenium forms like SeMet are known to be taken up at faster rates into roots than inorganic forms, further indicated that comparative changes as the percentages of the speciation concentration difference between bulked soil and rhizosphere to the concentration of bulked soil. Results showed that the relative changes of organic bound $\mathrm{Cu}, \mathrm{Zn}$ and $\mathrm{Pb}$ were, relatively higher in the infected rhizosphere than that of non infected rhizosphere (Jing et al., 2006 [33]). In addition to redox-conversions and methylation reactions, acidophilic iron- and sulfuroxidizing bacteria are able to leach high concentrations of zinc from contaminated soils. In synthetic media amended with heavy metal solution after treatment, Aspergillus niger allowed to grow it reduced the $\mathrm{Zn} 5.988 \mathrm{mg} / 1$ [34]. In addition to redox conversions, acidophilic iron and sulfur oxidizing bacteria are able to leach high concentration of zinc from contaminated soils [35].

\section{Conclusion}

In the above text a part of current environmental problem presented which is influencing the biodiversity of soil flora. Soil is sole medium of prosperity of human being. By several human activities and beneficiary approaches which are mentioned above releasing the effluents from Industries acting as disease for soil and environmental health. We all are connected to soil, directly or indirectly. Agaries and allied activity are possible only due to soil. Degrading soil quality may lead to feminine situation because it adversely affects the crop spurt. We all are well aware that soil productivity is not a meager problem, while it is menace to human population. For Rehabilitation and achieve prosperity of soil, the effluents must been treated prior to release in biosphere. In that way, microbes who were detained in contaminated soil have developed strategy to overcome the problem. By harnessing the microbial strength we could pursuit drastic condition.

In our Review the main objective is to represent the flora of contaminated soil with heavy metal $\mathrm{Zn}$. Influence on their biodiversity as well as on genetic makeup. We want to describe here strategy of these organisms to overcome these problems. As these organisms most potent competitor for environmental changes they evolved in such condition and harboring genetic information for solving problem and making partnership with their associated plants. Scientists who are working with these organisms can manipulate the genetics and add some resistance gene by transgenic technology for making them more potent to survive and removing of microbes. Industries must show accountability for such situation. Industrial effluents and charred material of industries is holocaust the soil ecology. The continuous hike in heavy metal in soil has gathered conspicuous situation. Industries must follow the laws and pacts of their waste disposal created by Environmental Protection Act (EPA).

\section{Further research must carry out on fields:}

a) Excavating strategies of microbes against heavy metals.

b) Biological parameter must rise for discharge of metals in soil.

c) Treatment of industrial waste prior to discharge.

\section{References}

[1] Current uses of Zinc. http://www.geocaching.com/seek/cache_details.aspx?guid=a5950ffb-e27f-4ba0-8568-c66470b6f69f . Assessed on 24 October 2012.

[2] Zinc natural occurrence http://www.zinc.org/basics/zinc natural occurrence . Assessed on 12 October 2012

[3] A. K. Krishna and P. K. Govil. Heavy metal contamination of soil around Pali Industrial Area, Rajasthan, India Environmental Geology 47, 2004, 38-44.

[4] C. O. Nweke, C. S. Alisi, J. C. Okolo, C. E. Nwanyanwu. Toxicity of Zinc to heterotrophic bacteria from a tropical river sediment Department of Microbiology, Federal University of Technology, P.M.B.1526, Owerri, Nigeria. Department of Biochemistry, Federal University of Technology, P.M.B. 1526, Owerri, Nigeria.

[5] D. Sobolev and M. F. T. Begonia. Effects of Heavy Metal Contamination upon Soil Microbes: Lead-induced Changes in General and Denitrifying Microbial Communities as Evidenced by Molecular Markers. International Journal of Environmental Research and Public Health 5(5), 2008, 450-456.

[6] J. Handelsman and P. W. Lawrence. Ecology and Industrial microbiology Microbial diversity sustaining the Earth and industry. Current Opinion in Microbiology, 5, 2002, 237-239.

[7] Y. Zhou, J.Yao, M. M. Choi, Y. Chen, H. Chen, R. Mohammad, R. Zhuang, F. Wang, T. Maskow and G. Zaray. 2010. A combination method to study microbial communities and activities in Zinc contaminated soil. University of Geosciences, Wuhan, China.

[8] J. Richard, M. Philip, J.Andrew. and C. John. Cultivation dependent and Independent Approaches for Determining Bacterial Diversity in Heavy Metal Contaminated Soil. Applied and Environmental Microbiology, 69(6), 2003.

[9] D. H. Nies. Microbial heavy metal resistance. Applied Microbiology and Biotechnology, 51, 1999, 730-750.

[10] W. B. Chui, M. Francesca, A. Farooq, O. Yumiko and S. Satoru. 2010. The Effect of Zinc Exposure on the Bacteria abundance and Proteolytic Activity in Seawater. Center for Marine Environmental Studies Ehime University. 
[11] C. O. Nweke, C. S. Alisi, J. C. Okolo, C. E. Nwanyanwu. Toxicity of Zinc to heterotrophic bacteria from a tropical river sediment Department of Microbiology, Federal University of Technology, P.M.B.1526, Owerri, Nigeria. Department of Biochemistry, Federal University of Technology, P.M.B. 1526, Owerri, Nigeria.

[12] S. Silver and L. T. Phung. Bacterial heavy metals resistance: new surprises. Annual Review of Microbiology, 50, $1996,753-789$.

[13] Mellano, M.A. and Cooksey, D.A. 1988. Induction of the Copper resistance operon from Pseudomonas syringae. Journal of Bacteriology, 170, 1988, 4399-4401.

[14] E. Diesel, M. Schreiber, M. J. R. Vander. Development of bacteria-based bioassays for arsenic detection in natural waters. Analytical and Bioanalytical Chemistry, 394, 2009, 687-693.

[15] N. J. Robinson, S. K. Whitehall and J. S. Cavet. Microbial metallothioneins. Advances in Microbial Physiology, 44, $2001,183-213$.

[16] K. Hirata, N. Tsuji and K. Miyamoto. Biosynthetic regulation of phytochelatins, heavy metal binding peptides. Journal of Bioscience and Bioengineering. 100, 2009, 593-599.

[17] A. Kumar, B. S. Bisht and V. D. Joshi. Biosorption of Heavy Metals by four acclimated microbial species, Bacillus species, Pseudomonas species, Staphylococcus species and Aspergillus niger. Journal of Biological and Environmental Science 4(12), 2010.

[18] M. Petr, S. Andrej, A. Vojtech, N Miroslav, T. Libuse, Z. Josef, H. Jaromir, P. Ivo, K. Rene. Influence of Zinc and Copper ions on Streptomyces bacteria Revealed by Electrochemistry. International Journal of Electrochemical Scienc, 6, 2011.

[19] A. Kumar, B. S. Bisht and V. D. Joshi. Biosorption of Heavy Metals by four acclimated microbial species, Bacillus species, Pseudomonas species, Staphylococcus species and Aspergillus niger. Journal of Biological and Environmental Science 4(12), 2010.

[20] N. Kishimoto, Y. Kosako, N. Wakao, T. Tano and A. Hiraishi. Transfer of Acidiphilium facilis and Acidiphilium aminolytica to the genus Acidocella gen. nov., and emendation of the genus Acidiphilium. Systematic Applied Microbiology, 18, 1995, 85-91.

[21] P. C. Banerjee, M. K. Ray, C. Koch, S. Bhattacharyya, S. Shivaji and E. Stackebrandt. Molecular characterization of two acidophilic heterotrophic bacteria isolated from a Copper mine of India. Systematic and Applied Microbiology, 19, 1996, 78-82.

[22] N. R. Mahapatra, and P. C. Banerjee. Extreme tolerance to Cadmium and high resistance to Copper, Nickel and Zinc in different Acidiphilium strains. Letters in Applied Microbiology, 23, 1996, 393-397.

[23] C. R. Edward, E. S. Selvam, and K. Omine. Isolation, Identification and characterization of heavy metal resistant bacteria from sewage. Internatiional joint symposium on "geodisaster and geoenvironment in Asia" JS-Fujuoka, 2009

[24] M. Petr, S. Andrej, A. Vojtech, N Miroslav, T. Libuse, Z. Josef, H. Jaromir, P. Ivo, K. Rene. Influence of Zinc and Copper ions on Streptomyces bacteria Revealed by Electrochemistry. International Journal of Electrochemical Scienc, 6, 2011.

[25] A. Mikolay and D. H. Nies. The ABC-transporter AtmA is involved in Nickel and Cobalt resistance of Cupriavidus metallidurans strain CH34. Antonie Van Leeuwenhoek, 96, 2009, 183-191.

[26] M. Bruins, S. Kapil and F. Oehme. Microbial resistance to metals in the environment. Ecotoxicology and Environmental Safety, 45, 2000, 198-207.

[27] A. Malik and R. Jaiswal. Metal resistance in Pseudomonas strains isolated from soil treated with industrial wastewater. World Journal of Microbiology and Biotechnology, 16, 2000.

[28] M. M. Rehab and E. Aly. Isolation and characterization of heavy-metal resistant microbes from roadside soil and phyllo plane. Journal of Basic Microbiology, 52, 2012.

[29] N. R. Mahapatra, and P. C. Banerjee. Extreme tolerance to Cadmium and high resistance to Copper, Nickel and Zinc in different Acidiphilium strains. Letters in Applied Microbiology, 23, 1996, 393-397.

[30] H. Azaizeh. Biomethylation and biotransformation of heavy metals by rhizosphere microbes. Journal of Environmental Quality, 32, 2003, 55-62.

[31] S. R. A. Abou, T. A. Delorme, J. S. Angle, R. L. Chaney, K. Ghanem, H. Moawad and H. A. Ghozlan. 2003. Phenotypic characterization of microbes in the rhizosphere of Alyssum murale . International Journal of Phytoremediation, 5(4), $2003,367-379$.

[32] J. Leong. Siderophores: their biochemistry and possible role in control of plant pathogens. Annual Review of Phytopathology 24(1), 1998, 187-209.

[33] Y. Jing, Z. li He and X. Yang. Role of soil rhizobacteria in phytoremediation of heavy metal contaminated soils. School of Natural Resource and Environment Science, Zhejiang University, Hangzhou 310029, China 2006.

[34] A. Kumar, B. S. Bisht and V. D. Joshi. Biosorption of Heavy Metals by four acclimated microbial species, Bacillus species, Pseudomonas species, Staphylococcus species and Aspergillus niger. Journal of Biological and Environmental Science 4(12), 2010.

[35] C. Loser, H. Seidel, P. Hoffmann and A. Zehnsdorf, Remediation of heavy metal- contaminated sediments by solid-bed bioleaching. Environmental Geology, 40, 2001, 643-650. 